Received: 4 April 2017

Accepted: 6 September 2017

Published online: 26 September 2017

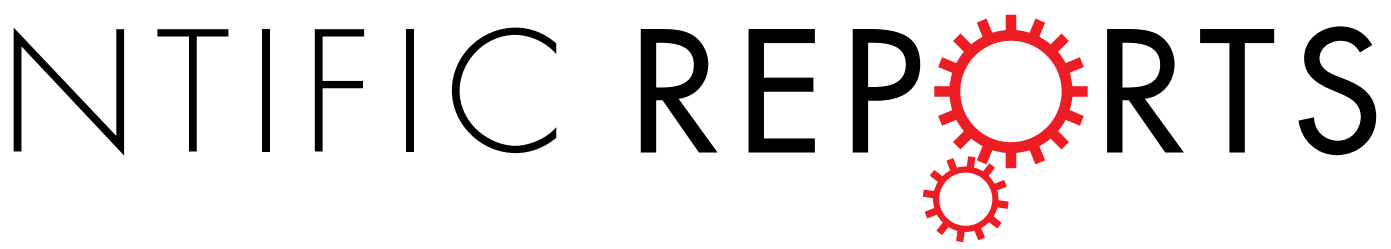

\title{
OPEN The Impact of Self-Reported Sleep on Caesarean Delivery in Women Undergoing Induction of Labour: A Prospective Study
}

\author{
Aimee Chuin Ai Teong ${ }^{1}$, Annabella Xinhui Diong ${ }^{1}$, Siti Zawiah Omar ${ }^{2} \&$ Peng Chiong Tan ${ }^{2}$
}

216 women admitted for labour induction were recruited to evaluate sleep duration and other sleep measures on Caesarean delivery risk. The Pittsburgh Sleep Quality Index, Berlin (Obstructive Sleep Apnoea (OSA), Epworth Sleepiness Scale, International Restless Leg Syndrome, Insomnia Symptom Questionnaires were applied. Short sleep duration was defined as reported night sleep length in the previous month below the study population median of 6 hours. After binomial analysis, Caesarean delivery after labour induction is associated with short sleep duration (RR 1.8, 95\% CI 1.1-2.9, $P=0.018$ ), nulliparity, Bishop Score, prepregnant $B M I$ and birth weight at $P<0.05$. After adjustment for nulliparity, Bishop Score, prepregnant BMI and birth weight, short sleep duration remains independently predictive of Caesarean delivery AOR 2.4, 95\% CI 1.1-5.0, $\mathrm{P}=0.026$. Women at high risk for OSA has a non-significant result on binomial analysis, $R R 1.6,95 \% \mathrm{Cl} 1.0-2.7, P=0.073$. In a sensitivity analysis which includes OSA in the multivariable logistic regression model, OSA's predictive effect is attenuated $A O R$ 1.2, 95\% $\mathrm{Cl} 0.4-3.2, \mathrm{P}=0.782$ whilst short sleep duration remains significant AOR 2.3 95\% CI 1.0-5.1, $\mathrm{P}=0.039$. Other evaluated sleep measures are not predictive of Caesarean delivery.

Lack of sleep has a major impact on general health: in a meta-analysis involving over a million subjects, short sleepers have a $12 \%$ greater risk of dying than those sleeping 7 to 8 hours per night ${ }^{1}$.

Across all months of pregnancy, poor sleep quality, insufficient night time sleep, daytime sleepiness, insomnia, sleep disordered breathing and restless legs syndrome are common ${ }^{2}$. In the third trimester as compared to early pregnancy, short sleep duration increases from $26.2 \%$ to $39.9 \%$ and poor overall sleep quality increases from $39.0 \%$ to $53.5 \%{ }^{3}$.

Short sleep duration during pregnancy is associated with adverse outcome. Nulliparous women who slept less than 6 hours at night were 4.5 times more likely to have Caesarean delivery and to have longer labours ${ }^{4}$. Women who slept less than 7 hours at night have increased risk of developing gestational diabetes ${ }^{5}$. Sleep duration 6 hours or less at night in early pregnancy is associated with increased mean blood pressure in the third trimester ${ }^{6}$. Sleep duration of 5 hours or less per night is a risk factor for preterm birth ${ }^{7}$.

Obstructive sleep apnoea in pregnant women is also associated with more frequent preeclampsia, preterm birth, Caesarean delivery and neonatal intensive care unit admission ${ }^{8}$.

Induction of labour is an increasingly common obstetric intervention. In the United States, the rate of induction of labour more than doubled from 1990 through 2010, from $9.6 \%$ to $23.8 \%{ }^{9}$. A 2014 meta-analysis of 31 trials finds that a policy of induction at 37-42 weeks of gestation is associated with a significant reduction in the risk of Caesarean section compared with expectant management ${ }^{10}$. This finding may precipitate a further increase in the rate of labour induction.

We hypothesize that preceding short sleep duration will negatively impact the response to labour induction resulting in a higher Caesarean delivery rate. We sought to evaluate the association of short sleep duration and other sleep measures to Caesarean delivery in women undergoing labour induction.

${ }^{1}$ Faculty of Medicine, University of Malaya, Lembah Pantai, Kuala Lumpur, Malaysia. ${ }^{2}$ Department of Obstetrics and Gynaecology, Faculty of Medicine, University of Malaya, Lembah Pantai, Kuala Lumpur, Malaysia. Aimee Chuin Ai Teong and Annabella Xinhui Diong contributed equally to this work. Correspondence and requests for materials should be addressed to P.C.T. (email: pctan@um.edu.my) 


\section{Methods}

This study was conducted in full compliance with the principles proclaimed in the Declaration of Helsinki on human research. Consent was informed and collected in the written format from all participants. Recruitment was from $3^{\text {rd }}$ November 2014 to $29^{\text {th }}$ April 2015.

Sample size calculation. We opted to dichotomize our participants to short versus good sleep duration categories based on the 50th centile (median) cut-off for reported night sleep within our study population. As data on the effect of short sleep duration on Caesarean delivery following induction of labour is not available, we use as guidance an earlier paper investigating sleep duration in pregnancy and labour outcomes ${ }^{4}$; women in that study within the approximate upper half of sleep duration compared to women in the lower half has a Caesarean delivery rate of $35.1 \%(20 / 57)$ v. $10.8 \%(8 / 74)$. Applying the Chi Square test, alpha $=0.05$, power $=0.8$, and $\mathrm{P}_{0}=10.8 \%$, $\mathrm{P}_{1}=35.1 \%$ and a case to control ratio of 1 to 1 , a total of 92 participants are required for a powered study based on these parameters ${ }^{11}$. As we planned to perform multivariable logistic regression analysis with likely multiple predictor variables incorporated in the model, we aim to have 50 Caesarean deliveries in our study population (sufficient for analysis of 5 predictor variables based on the 10 events per predictor variable rule for multivariable logistic regression analysis $\left.{ }^{12}\right)$. A previous report from our hospital showed a $26.1 \%(69 / 264)$ Caesarean section rate after labour induction in a mixed population of nulliparas and multiparas ${ }^{13}$. A sample size of $192(50 / 0.261)$ is calculated to attain 50 Caesarean deliveries. Building in a 10\% margin for drop-outs, we aimed to recruit at least $213(192 / 0.9)$ participants.

Questionnaires. The following sleep related questionnaires were used in an interview around the start of induction: Pittsburgh Sleep Quality Index (PSQI), the Epworth Sleepiness Scale (ESS), Berlin Questionnaire for Sleep Apnoea, the International Restless Legs Syndrome (IRLS) Rating Scale, and the Insomnia Symptom Questionnaire (ISQ). These tools are used in combination in recent studies to assess the global impact of sleep on pregnancy outcome $\mathrm{e}^{2,3,14}$.

The PSQI (19-item questionnaire) is validated for use in pregnancy ${ }^{15}$ and assessed sleep quality over the last month. A global score $>5$ indicates poor sleep quality and it has been shown to have a diagnostic sensitivity of $89.6 \%$ and a specificity of $86.5 \%$ in distinguishing between good and poor sleepers ${ }^{16}$. Sleep duration was obtained from a stem answer within the PSQI questionnaire; the hours of sleep at night was recorded in whole numbers and referred to sleep duration in the last month.

The ESS is a widely used measure of recent daytime sleepiness, with scores ranging from 0 to 24 . Excessive daytime sleepiness is defined as a total score of $\geq 10^{17}$. It is validated in first trimester pregnancy ${ }^{18}$, and used in several last trimester sleep studies ${ }^{2,3}$.

The Berlin Questionnaire is scored in 3 categories; when a participant has at least 2 categories with a positive score, the case categorization is high risk for obstructive sleep apnoea (OSA $)^{19}$. Berlin sleep questionnaire is predictive in later pregnancy for obstructive sleep apnoea ${ }^{20}$.

IRLS Rating Scale is a validated rating scale for Restless Leg Syndrome in the past 1 week, comprising of 10 questions which produces an overall score could range from 0 to $40^{21}$. We opted to dichotomize our participants to absence (score 0 ) or presence of Restless Leg Syndrome (score 1 to 40).

The ISQ is a 13-item self-report instrument designed to identify insomnia in the past month and is validated in pregnant women. Respondents are classified into insomnia disorder and no insomnia disorder ${ }^{22}$.

Recruitment. Women were recruited by co-authors (AT and AD) based on investigator availability basis on their admission for planned labour induction. Other inclusion criteria are reassuring fetal status on pre-induction cardiotocogram, 37 to 42 weeks' gestation, age 18 to 45 years, singleton fetus, intact membranes and cephalic presentation. The exclusion criteria are previous caesarean section, intrauterine fetal death or known gross fetal anomaly, known pre-pregnancy sleep or psychiatric disorders.

Patients' clinical notes were scrutinised for eligibility. A patient information sheet was supplied to all women who were approached for recruitment. The recruiter answered any oral queries. Written consent was obtained from all participants. Demographic, clinical and questionnaire data were collected.

Labour induction for study participants follows our standard institution protocol. Briefly, patients are typically admitted at about 8 o'clock on the morning of induction. Cardiotocography is performed and induction of labour is only started if the cardiotocograph is reassuring. Method of induction of labour is decided as guided by cervical favourability. Dinoprostone (3 mg) pessary is typically used for cervical ripening and if the cervix is favourable, amniotomy is performed followed by titrated oxytocin infusion to induce labour. The details of the induction protocol is described in a published study from our centre ${ }^{13}$.

Responses to study questionnaires were not revealed to care providers. The investigators were not involved in the care of the participants. Post-induction outcomes were retrieved from medical notes after delivery.

Analysis. Data were entered into statistical software package SPSS version 22.0 (SPSS Inc., Chicago, IL, USA). Analysis was performed after dichotomisation into Caesarean delivery vs. vaginal delivery after labour induction. A binomial analysis was first performed to evaluate predictors of Caesarean delivery from relevant demographics and sleep questionnaires' findings. We planned to include all predictors with $\mathrm{p}<0.05$ on binomial analysis in the model for our primary multivariable logistic regression analysis. We expressed the data as mean and standard deviation for normally distributed continuous measures, median and interquartile range for ordinal or non-normally distributed continuous variables and frequencies and proportions for categorical measures. Chi square test was used for analysing differences in proportions for categorical variables. Student t test and Mann Whitney $U$ test was used to analyse means for normally distributed and ordinal or non-normally distributed continuous variables respectively. $\mathrm{P}<0.05$ is taken as the level of statistical significance. 


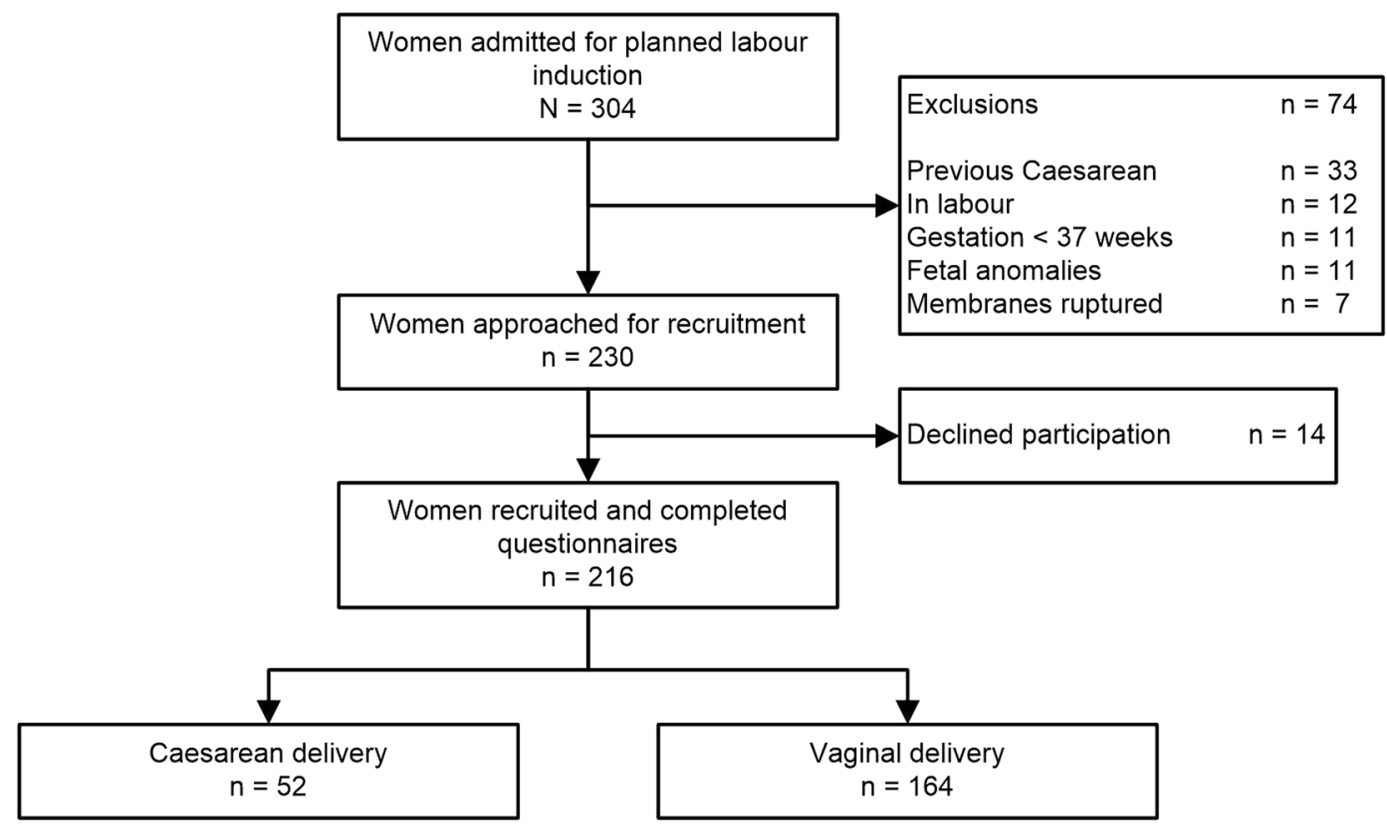

Figure 1. Recruitment Flow chart for a Prospective Study in Women Undergoing Labour Induction on Impact of Sleep Duration and Quality on Caesarean delivery.

Ethics approval. Ethics oversight was provided by the Medical Ethics Committee of University of Malaya Medical Centre who granted approval on 11 September 2014 (MECID No. 20147-371).

Data Availability. Data may be made available on request subject to approval by the Ethics Committee of the University Malaya Medical Centre on participants' confidentiality.

\section{Results}

The recruitment and flow through the study is depicted in Fig. 1. 216 respondents were recruited. We stopped recruitment on achieving our target sample size.

Table 1 shows the baseline characteristics of the study population including the findings of the sleep questionnaires. The median (approximate $50^{\text {th }}$ centile) reported night sleep duration for our study population was 6 hours. Therefore based on a priori $50^{\text {th }}$ centile cut-off, we classify short sleep duration as $<6$ hours and good sleep duration as $\geq 6$ hours; $47.2 \%$ reported less than 6 hours of sleep a night during the previous month.

Table 2 depicts the predictor characteristics dichotomized to all-cause Caesarean delivery compared with vaginal delivery (inclusive of spontaneous and instrumental) after induction of labour. On binomial analysis, Caesarean delivery after labour induction is significantly associated $(\mathrm{P}<0.05)$ with nulliparity, pre-pregnancy BMI, Bishop Score, short sleep duration ( $<6$ hours) and birth weight. Short sleep duration has a relative risk (RR) of 1.8, 95\% Confidence Interval (CI) $1.1-2.9 ; \mathrm{P}=0.018$ for Caesarean delivery. Berlin OSA stratification to high risk for OSA is a non-significant result RR 1.6, 95\% CI 1.0-2.7; $\mathrm{P}=0.073$ as predictor of Caesarean delivery. Poor sleep quality (assessed by PSQI), day time sleepiness (assessed by ESS), presence of symptoms of restless leg syndrome (assessed by IRLS Rating Scale) and insomnia (assessed by ISQ) were not predictive of Caesarean delivery. Following multivariable logistic regression incorporating the five aforementioned variables with binomial analysis $\mathrm{P}<0.05$, short sleep duration adjusted odds ratio (AOR) $2.4,95 \% \mathrm{CI} 1.1-5.0, \mathrm{P}=0.026$ remains predictive of Caesarean delivery.

Post hoc, a sensitivity analysis was performed incorporating predictor characteristics with $\mathrm{P}<0.1$ (including Berlin OSA and ethnicity) on binomial analysis to check whether the finding of short sleep duration as a predictor for Caesarean delivery after labour induction is robust after adjustment for a larger number of potential confounders. Short sleep duration's AOR 2.3, 95\% CI 1.0-5.1, P =0.039 for Caesarean delivery is not materially changed in this model. The predictive value of obstructive sleep apnoea is severely attenuated after adjustment for short sleep duration and other potential confounders AOR 1.2 95\% CI 0.4-3.2; P=0.782 (Supplementary Table 1).

Caesarean delivery rates after labour induction were $43 / 118$ (36.4\%) and 9/98 (9.2\%) in our nulliparous and multiparous participants respectively. We performed an exploratory analysis based on nulliparous women at high risk for Caesarean delivery to evaluate the effect of sleep measures (Supplementary Table 2). Despite an almost halving of the sample size on restricting analysis to only nulliparas which might have reduced statistical power, on binomial analysis, the association of short sleep duration to Caesarean delivery was RR 1.9, 95\% CI 1.2-3.2, $\mathrm{P}=0.008$ and high risk OSA RR 1.8, 95\% CI 1.1-2.9, $\mathrm{P}=0.036$ were significant at the $\mathrm{P}<0.05$ level. The median sleep duration was also significantly shorter (5 [IQR 4-5] vs. 6 [IQR 5-7], P=0.018) and the Chi Square for trend (after categorization into sleep duration quartiles) shows a significant inverse trend $(\mathrm{P}=0.014)$ in nulliparas who had Caesarean delivery compared to vaginal delivery after labour induction. Incorporating short sleep duration, high risk OSA, prepregnant BMI, birth weight, Bishop Score and ethnicity into the multivariable logistic 


\begin{tabular}{|l|l|}
\hline Characteristic & Participants (N=216) \\
\hline Age(years, mean \pm SD) & $31.2 \pm 4.5$ \\
\hline Nulliparous & $118(54.6)$ \\
\hline Ethnicity & $129(59.7)$ \\
\hline Malay & $29(13.4)$ \\
\hline Chinese & $43(19.9)$ \\
\hline Indian & $15(6.9)$ \\
\hline Others & $25.1 \pm 5.7$ \\
\hline Prepregnancy BMI $\left(\mathrm{kg} / \mathrm{m}^{2}\right.$, mean \pm SD) \\
\hline Gestational Weight Gain $(\mathrm{kg} / \mathrm{m} 2$, \\
mean \pm SD)
\end{tabular}

Table 1. Characteristics of study population. Values are stated as $n(\%)$, median [Interquartile Range, IQR] or mean \pm standard deviation. ${ }^{*} \mathrm{n}=205$ (11 women were unable to recall prepregnancy weight/gestational weight gain/height). ${ }^{\dagger}$ Includes oligohydramnios, suspected IUGR, reduced fetal movement and suboptimal umbilical artery on Doppler examination. ${ }^{\ddagger}$ Includes a single case of ripening with Foley catheter. ${ }^{\S} n=213$ (Unable to classify 3 women sleep apnea risks due to missing BMI data).

regression analysis model, short sleep duration remains independently predictive for Caesarean delivery AOR $2.8,95 \% \mathrm{CI} 1.1-7.1, \mathrm{P}=0.031$ whilst the predictive value of being at high risk OSA is attenuated AOR 1.2, 95\% CI $0.4-4.3, \mathrm{P}=0.75$. The impact of short sleep duration in nulliparas for predicting Caesarean delivery after labour induction appears marginally stronger than when the entire mixed nulliparous and multiparous study population was considered AOR 2.8, 95\% CI 1.1-7.1 v AOR 2.3, 95\% CI 1.0-5.1. 


\begin{tabular}{|c|c|c|c|c|c|c|}
\hline \multirow[b]{2}{*}{ Variable } & \multirow{2}{*}{$\begin{array}{l}\text { Caesarean } \\
\text { Delivery } \\
(\mathbf{n}=52)\end{array}$} & \multirow{2}{*}{$\begin{array}{l}\text { Vaginal } \\
\text { Delivery } \\
(\mathrm{n}=164)\end{array}$} & \multirow[b]{2}{*}{ P Value } & \multirow[b]{2}{*}{ RR $(95 \% \mathrm{CI})$} & \multicolumn{2}{|c|}{$\begin{array}{l}\text { Multivariable Logistic } \\
\text { Regression Analysis }\end{array}$} \\
\hline & & & & & AOR $(95 \% \mathrm{CI})$ & Pvalue \\
\hline Age (years, mean \pm SD) & $30.8 \pm 3.9$ & $31.4 \pm 4.7$ & 0.438 & & & \\
\hline Nulliparity & $43(82.7)$ & $75(45.7)$ & $<0.001$ & $4.0(2.0-7.7)$ & $11.9(4.2-33.5)$ & $<0.001$ \\
\hline \multicolumn{7}{|l|}{ Ethnicity } \\
\hline Malay & $28(53.8)$ & $101(61.6)$ & 0.050 & & & \\
\hline Chinese & $4(7.7)$ & $25(15.2)$ & & & & \\
\hline Indian & $17(32.7)$ & $26(15.9)$ & & & & \\
\hline Others & $3(5.8)$ & $12(7.3)$ & & & & \\
\hline Prepregnancy BMI $(\mathrm{kg} / \mathrm{m} 2, \text { mean } \pm \mathrm{SD})^{*}$ & $27.1 \pm 5.8$ & $24.6 \pm 5.6$ & 0.007 & & $1.1(1.0-1.2)$ & 0.002 \\
\hline Gestational Weight Gain $(\mathrm{kg} / \mathrm{m} 2 \text {, mean } \pm \mathrm{SD})^{*}$ & $13.4 \pm 5.4$ & $13.1 \pm 5.8$ & 0.772 & & & \\
\hline Gestational age (weeks, mean \pm SD) & $39.4 \pm 1.4$ & $39.2 \pm 1.3$ & 0.413 & & & \\
\hline \multicolumn{7}{|l|}{ Indications for Induction of Labour } \\
\hline Diabetes mellitus & $26(50.0)$ & $72(43.9)$ & 0.113 & & & \\
\hline Prolonged pregnancy & $15(28.8)$ & $34(20.7)$ & & & & \\
\hline Hypertension & $7(13.5)$ & $18(11.0)$ & & & & \\
\hline Non-reassuring fetal status ${ }^{\dagger}$ & $4(7.7)$ & $33(20.1)$ & & & & \\
\hline Others & $0(0.0)$ & $7(4.3)$ & & & & \\
\hline Bishop score (median [IQR]) & $1[1-2]$ & $2[1-3]$ & 0.012 & & $1.0(0.7-1.3)$ & 0.812 \\
\hline \multicolumn{7}{|l|}{ Method of labour induction } \\
\hline Vaginal dinoprostone $^{*}$ & $49(94.2)$ & $152(92.7)$ & 0.702 & $1.2(0.4-3.5)$ & & \\
\hline Amniotomy & $3(5.8)$ & $12(7.3)$ & & & & \\
\hline \multicolumn{7}{|l|}{ Reported Night Sleep } \\
\hline Duration (hours, median [IQR]) & $5[4-6]$ & $6[5-7]$ & 0.093 & & & \\
\hline \multicolumn{7}{|l|}{ Median cut-off } \\
\hline Short Sleep Duration $<6$ hours & $32(61.5)$ & $70(42.7)$ & 0.018 & $1.8(1.1-2.9)$ & $2.4(1.1-5.0)$ & 0.026 \\
\hline Good Sleep Duration $\geq 6$ hours & $20(38.5)$ & $94(57.3)$ & & & 1 & \\
\hline \multicolumn{7}{|l|}{ Quartile cut-offs } \\
\hline$<4$ hours & $14(26.9)$ & $32(19.5)$ & $0.062^{5}$ & & & \\
\hline 5 hours & $18(34.6)$ & $38(23.2)$ & & & & \\
\hline 6 hours & $8(15.4)$ & $45(27.4)$ & & & & \\
\hline$\geq 7$ hours & $12(23.1)$ & $49(29.9)$ & & & & \\
\hline \multicolumn{7}{|l|}{ Pittsburgh Sleep Quality Index } \\
\hline Poor Sleep Quality & $35(67.3)$ & $115(70.1)$ & 0.701 & $0.9(0.5-1.5)$ & & \\
\hline Good Sleep Quality & $17(32.7)$ & $49(29.9)$ & & & & \\
\hline \multicolumn{7}{|l|}{ Berlin Risk of Sleep Apneal } \\
\hline High Risk & $14(28.0)$ & $27(16.6)$ & 0.073 & $1.6(1.0-2.7)$ & & \\
\hline Low Risk & $36(72.0)$ & $136(83.4)$ & & & & \\
\hline \multicolumn{7}{|l|}{ Epworth Sleepiness Scale } \\
\hline Daytime Sleepiness & $10(19.2)$ & $23(14.0)$ & 0.363 & $1.3(0.7-2.4)$ & & \\
\hline Normal & $42(80.8)$ & $141(86.0)$ & & & & \\
\hline \multicolumn{7}{|l|}{ Restless Leg Syndrome } \\
\hline Present & $29(55.8)$ & $91(55.5)$ & 0.972 & $1.0(0.6-1.6)$ & & \\
\hline Absent & $23(44.2)$ & $73(44.5)$ & & & & \\
\hline \multicolumn{7}{|l|}{ Insomnia Symptom Questionnaire } \\
\hline Insomnia Disorder & $11(21.2)$ & $29(17.7)$ & 0.574 & $1.2(0.7-2.1)$ & & \\
\hline None & $41(78.8)$ & $135(82.3)$ & & & & \\
\hline Birth Weight (100 grams, mean \pm SD) & $31.5 \pm 4.5$ & $29.9 \pm 4.6$ & 0.025 & & $1.1(1.0-1.2)$ & 0.012 \\
\hline
\end{tabular}

Table 2. Participants' Characteristics Dichotomized into Caesarean Delivery and Vaginal Delivery Groups. Values are stated as $\mathrm{n}(\%)$, median [Interquartile Range, IQR] or mean \pm standard deviation. Analysis was by t-test for continuous variables, Mann-Whitney U Test for ordinal data, Chi-square test for categorical data, and chi-square test for trend for sequential categorical data. Multivariable logistic regression analysis on 205 respondents were used to identify independent predictors for caesarean delivery using all variables with a crude $\mathrm{p}<0.05$. Adjusted odd ratio is shown for all variables used in the model. $* n=205$ ( 11 women were unable to recall prepregnancy weight/gestational weight gain/height). ${ }^{\dagger}$ Includes oligohydramnios, suspected IUGR, reduced fetal movement and suboptimal umbilical artery on Doppler examination. ${ }^{*}$ Includes a single case of ripening with the Foley catheter. $§ p$ value obtained from Chi Square for trend. $\|_{n}=213$ (Unable to classify 3 women into high or low risk for sleep apnea due to missing BMI data). 
Table 3 shows the correlation of sleep duration with selected other characteristics and labour outcomes as post hoc exploration. With short sleep duration, the induction to delivery interval (after excluding Caesarean delivery indicated by non-reassuring fetal status) is longer by an average 4 hours; (mean \pm standard deviation) 23.9 hours \pm 13.3 vs 19.9 hours $\pm 12.6, \mathrm{p}=0.036$. On binomial analysis, short sleep duration is inversely associated with low birth weight $(<2.5 \mathrm{~kg}) \mathrm{RR} 0.4,95 \% \mathrm{CI} 0.2-1.0, \mathrm{P}=0.048$, higher gestational weight gain but prepregnancy BMI is similar. Short sleep duration was not predictive of epidural use, postpartum haemorrhage, umbilical cord arterial blood $\mathrm{pH}$ or base excess or newborn Apgar score.

\section{Discussion}

We find that Caesarean delivery after labour induction is associated with short sleep duration ( $<6$ hours night sleep reported) after adjustment for parity, pre-pregnancy BMI, bishop score, and birth weight AOR 2.4, 95\% CI 1.1-5.0, $\mathrm{P}=0.026$ (Table 2). Sensitivity analysis incorporating 2 additional variables, ethnicity and Berlin OSA, shows no material change to the predictive value of short sleep duration (AOR 2.3, 95\% CI 1.0-5.1, $\mathrm{P}=0.039$ ) whilst the finding for OSA shows severe attenuation (AOR 1.2, 95\% CI 0.4-3.2, P = 0.782) after adjustment. The induction to delivery interval is longer by 4 hours on average in women with short sleep duration but other adverse maternal and fetal outcomes were similar (Table 3). Our findings suggest the primacy of sleep duration over other sleep measures in the prediction of poor labour induction outcome.

There is limited literature on the impact of sleep on labour induction outcome. We performed a PubMed (http://www.ncbi.nlm.nih.gov/pubmed) search on the 21st August 2016 with the terms "sleep and labour induction or sleep and labour induction" -46 articles were retrieved. We found only one paper that reported a secondary analysis (relative risk not reported) of sleep duration in a subset population who had labour induction ${ }^{23}$.

We derived RR 3.2 for all-case Caesarean delivery in pregnant with women short sleep duration (based on approximate $50^{\text {th }}$ centile sleep duration cut-offs in their population) from a seminal 2004 paper $^{4}$ and applied that in our sample size calculation. Their study population of 131 was exclusively nulliparous with sleep assessed by actigraph whilst ours had 216 women; nulliparous to parous split of 55\% to $45 \%$ with self-reported night sleep duration. Poor sleep duration women in our study has AOR 2.4 for Caesarean delivery after labour induction. In exploratory analysis, nulliparous women with short sleep duration in our study has AOR 2.8 for Caesarean delivery after labour induction. The findings on the impact size of short sleep duration against Caesarean delivery across our study and theirs are broadly similar. Our longer induction to delivery time in short sleep duration women is also consistent with their finding that severely disrupted sleep is associated with longer labours.

A 2012 report on the effects of sleep quality and duration in late pregnancy on labour and fetal outcome states that in most women with more than 8 hours sleep had normal vaginal delivery with induction ${ }^{23}$. The authors did not report on relative risk and it was not possible on reading the paper to calculate it. $66.4 \%$ of their study population reported more than 8 of sleep compared to only $13.9 \%$ in our population.

A 2016 report on a longitudinal study of 688 healthy Chinese women with a 55.5\% Caesarean delivery rate finds sleep quality particularly in the second trimester to be strongly associated with Caesarean delivery. Short sleep time is not associated with Caesarean delivery but with preterm births ${ }^{24}$. These findings are in contrast to ours that Caesarean delivery after labour induction is predicted by short sleep duration but not poor sleep quality. For their healthy population of nulliparas and multiparas, the Caesarean delivery rate is a relatively high $55.5 \%{ }^{24}$ suggesting that their considerations to proceed with a Caesarean is likely to be substantially different from ours.

In a 2014 report of a prospective study with 120 third trimester women using PSQI questionnaire poor sleep quality was significantly associated with vacuum-assisted delivery but not significantly associated with Caesarean section ${ }^{25}$. Our sleep quality using PSQI findings similarly show no association with Caesarean delivery after labour induction.

A 2014 meta-analysis on obstructive sleep apnoea and the risk of perinatal outcomes involving 5 cohort studies with 977 women reports a Caesarean delivery RR 1.87; 95\% CI 1.52 to $2.29^{8}$. In our study, the binomial analysis for obstructive sleep apnoea was a non-significant RR 1.6, 95\% CI 1.0-2.7 broadly similar to meta-analysis finding but there is severe attenuation after adjusting for short sleep duration and other potential confounders so that OSA was no longer predictive. Our data shows the primacy of short sleep duration over OSA and other sleep related measures as a predictor of failed induction.

Other studies have not demonstrated a significant association between poor sleep measures and adverse pregnancy outcome; sleep deprivation ( $<6$ hours) was not a significant predictor of Caesarean section after adjustment ${ }^{26}$, and sleep duration was not associated to delivery mode ${ }^{27}$. None of these studies evaluated women undergoing labour induction though most used similar sleep measurement tools.

To our knowledge, the underlying mechanism through which sleep factors can directly impact on adverse pregnancy outcome and specific to our study, on Caesarean delivery and prolongation of labour after labour induction is not known and an interesting area for future research.

For our strength, we evaluated poor sleep duration as a primary predictor alongside a range of sleep measures (sleep quality, obstructive sleep apnoea, daytime sleepiness, restless leg and insomnia) with adjustment as appropriate. The interviews were done by 2 investigators (AT and $\mathrm{AD}$ ) with a standardised method. Recruitment uptake is high, $94 \%$ of those eligible and approached agreed to participate. All participants completed their interview. Our data set is replete. In our multivariable logistic regression model we incorporated the significant variables on binomial analysis. Our study is powered. There were 52 Caesarean deliveries; our primary multivariable regression analysis incorporated 5 predictor variables $(\mathrm{P}<0.05)$, within the 10 events per variable rule for logistic analysis (which may be too conservative ${ }^{12}$ ). Our sensitivity analysis incorporating all predictor variables $\mathrm{P}<0.1$ comprised 7 variables in the model.

As for our limitations, we used a subjective measure with night sleep duration self- reported in integer hours and hence potentially open to bias. Questionnaire-derived reports of sleep hours in pregnancy may not reflect objectively measured sleep time ${ }^{28}$; however self-reported sleep hours is commonly used in pregnancy studies ${ }^{2,3}$. Recent population based studies investigating adverse pregnancy outcome including Caesarean delivery to sleep have used 


\begin{tabular}{|c|c|c|c|c|}
\hline Variable & \begin{tabular}{|l|} 
Short Sleep \\
Duration \\
$(\mathbf{n}=102)$
\end{tabular} & \begin{tabular}{|l|} 
Good Sleep \\
Duration \\
$(\mathrm{n}=114)$
\end{tabular} & $\begin{array}{l}\mathbf{P} \\
\text { value }\end{array}$ & RR $(95 \% \mathrm{CI})$ \\
\hline $\begin{array}{l}\text { Induction to delivery Interval (hours, } \\
\text { mean } \pm \mathrm{SD})^{*}\end{array}$ & $23.9 \pm 13.3$ & $19.9 \pm 12.6$ & 0.036 & \\
\hline Prepregnancy BMI $\left(\mathrm{kg} / \mathrm{m}^{2}, \text { mean } \pm \mathrm{SD}\right)^{\dagger}$ & $25.4 \pm 5.4$ & $24.8 \pm 6.0$ & 0.444 & \\
\hline 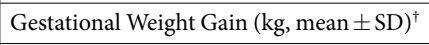 & $14.4 \pm 5.9$ & $12.1 \pm 5.3$ & 0.003 & \\
\hline Bishop Score (median [IQR]) & $2[1-2]$ & $2[1-3]$ & 0.194 & \\
\hline Birth Weight $(\mathrm{kg}$, mean $\pm \mathrm{SD})$ & $3.1 \pm 0.5$ & $3.0 \pm 0.4$ & 0.104 & \\
\hline Low birth weight $(<2.5 \mathrm{~kg}$ vs. $\geq 2.5)$ & $6(5.9)$ & $16(14.0)$ & 0.048 & $0.4(0.2-1.0)$ \\
\hline High birth weight $(\geq 3.6 \mathrm{~kg} \text { vs. }<3.6 \mathrm{~kg})^{\ddagger}$ & $14(13.7)$ & $9(7.9)$ & 0.165 & $1.7(0.8-3.8)$ \\
\hline Epidural Use & 19 (18.6) & $16(14.0)$ & 0.360 & $1.3(0.7-2.4)$ \\
\hline Estimated blood loss $(\mathrm{ml}, \text { mean } \pm \mathrm{SD})^{\varsigma}$ & $339.8 \pm 228.7$ & $312.3 \pm 200.8$ & 0.353 & \\
\hline$>500 \mathrm{mls}$ & $17(16.8)$ & $10(9.1)$ & 0.093 & $1.9(0.9-3.9)$ \\
\hline \multicolumn{5}{|l|}{ Umbilical cord arterial blood } \\
\hline $\mathrm{pH}(\mathrm{mean} \pm \mathrm{SD})^{\|}$ & $7.3 \pm 0.1$ & $7.3 \pm 0.1$ & 0.824 & \\
\hline Cord $\mathrm{pH}<7$ & $1(1.0)$ & $1(0.9)$ & 0.926 & $1.1(0.1-18.0)$ \\
\hline Cord Base deficit (mean \pm SD) & $.3 .2 \pm 3.1$ & $.3 .5 \pm 2.7$ & 0.480 & \\
\hline Base deficit $<8 \mathrm{mmol} / \mathrm{L}$ & $7(7.0)$ & $7(6.2)$ & 0.813 & $1.1(0.4-3.1)$ \\
\hline \multicolumn{5}{|l|}{ Apgar Score } \\
\hline $1 \min <4$ & $2(2.0)$ & $1(0.9)$ & 0.497 & $2.2(0.2-24.3)$ \\
\hline
\end{tabular}

Table 3. Reported Night Sleep Duration and Secondary Outcomes After Labour Induction. Values are stated as $\mathrm{n}(\%)$, median [Interquartile Range, IQR] or mean \pm standard deviation. Analysis was by $\mathrm{t}$-test for continuous. variables, Mann-Whitney U Test for ordinal data, and Chi-square test for categorical data. *n $=191$ ( 25 cases excluded for caesarean section for non reassuring fetal status. ${ }^{\dagger} n=205$ (11 women were unable to recall prepregnancy weight and gestational weight gain. ${ }^{\ddagger} 3.6 \mathrm{~kg}=90$ th centile of birth weight. ${ }^{\$} \mathrm{n}=211$ ( 5 cases of missing data). $\|_{n}=214$ ( 2 cases of missing data). ${ }^{n} \mathrm{n}=213$ ( 3 cases of missing data). ${ }^{\#}$ Relative risk cannot be generated as observed count is 0 .

less precise retrospective hospital records ${ }^{29}$ and electronic perinatal record ${ }^{30}$ to identify maternal sleep issues. We planned analysis based on $50^{\text {th }}$ centile cut-offs to minimize reliance on absolute sleep duration as we are aware that studies on short sleep duration to adverse pregnancy outcomes have reported different absolute cut-offs of 5 hours or less 7 , less than 6 hours $^{4}, 6$ hours or less ${ }^{6}$, less than 7 hours ${ }^{5}$ and less than 8 hours $^{23}$. Although extensively used in the 'sleep in pregnancy' literature, some of the questionnaires we used have not been validated for sleep disorders in pregnancy ${ }^{21}$ or more specifically in late pregnancy ${ }^{18,22}$. PSQI is validated in the last month of pregnancy ${ }^{15}$ and Berlin questionnaire is predictive in later pregnancy ${ }^{20}$. It has also been suggested that studies of sleep duration effects on labour and pregnancy outcomes require a consideration of the amount of both daytime and night time sleep ${ }^{27}$.

\section{Conclusion}

Caesarean delivery after labour induction and a longer induction to delivery interval are associated with reported short night sleep duration in the last month.

\section{References}

1. Cappuccio, F. P., D’Elia, L., Strazzullo, P. \& Miller, M. A. Sleep duration and all-cause mortality: a systematic review and metaanalysis of prospective studies. Sleep 33, 585-592 (2010).

2. Mindell, J. A., Cook, R. A. \& Nikolovski, J. Sleep patterns and sleep disturbances across pregnancy. Sleep medicine 16, 483-488, https://doi.org/10.1016/j.sleep.2014.12.006 (2015).

3. Facco, F. L., Kramer, J., Ho, K. H., Zee, P. C. \& Grobman, W. A. Sleep disturbances in pregnancy. Obstetrics and gynecology 115 , 77-83, https://doi.org/10.1097/AOG.0b013e3181c4f8ec (2010).

4. Lee, K. A. \& Gay, C. L. Sleep in late pregnancy predicts length of labor and type of delivery. American journal of obstetrics and gynecology 191, 2041-2046, https://doi.org/10.1016/j.ajog.2004.05.086 (2004).

5. Reutrakul, S. et al. Sleep disturbances and their relationship to glucose tolerance in pregnancy. Diabetes care 34, 2454-2457, https:// doi.org/10.2337/dc11-0780 (2011).

6. Williams, M. A. et al. Associations of early pregnancy sleep duration with trimester-specific blood pressures and hypertensive disorders in pregnancy. Sleep 33, 1363-1371 (2010).

7. Micheli, K. et al. Sleep patterns in late pregnancy and risk of preterm birth and fetal growth restriction. Epidemiology 22, 738-744, https://doi.org/10.1097/EDE.0b013e31822546fd (2011).

8. Xu, T., Feng, Y., Peng, H., Guo, D. \& Li, T. Obstructive sleep apnea and the risk of perinatal outcomes: a meta-analysis of cohort studies. Scientific reports 4, 6982, https://doi.org/10.1038/srep06982 (2014).

9. Osterman, M. J. \& Martin, J. A. Recent declines in induction of labor by gestational age. NCHS data brief 1-8 (2014).

10. Wood, S., Cooper, S. \& Ross, S. Does induction of labour increase the risk of caesarean section? A systematic review and metaanalysis of trials in women with intact membranes. BJOG: an international journal of obstetrics and gynaecology 121, 674-685, discussion 685, https://doi.org/10.1111/1471-0528.12328 (2014).

11. Dupont, W. D. \& Plummer, W. D. Jr. Power and sample size calculations. A review and computer program. Controlled clinical trials 11, 116-128 (1990).

12. Vittinghoff, E. \& McCulloch, C. E. Relaxing the rule of ten events per variable in logistic and Cox regression. American journal of epidemiology 165, 710-718, https://doi.org/10.1093/aje/kwk052 (2007). 
13. Tan, P. C., Jacob, R. \& Omar, S. Z. Membrane sweeping at initiation of formal labor induction: a randomized controlled trial. Obstetrics and gynecology 107, 569-577, https://doi.org/10.1097/01.AOG.0000200094.89388.70 (2006).

14. Sharma, S. K. et al. Sleep disorders in pregnancy and their association with pregnancy outcomes: a prospective observational study. Sleep \& breathing = Schlaf \& Atmung 20, 87-93, https://doi.org/10.1007/s11325-015-1188-9 (2016).

15. Skouteris, H., Wertheim, E. H., Germano, C., Paxton, S. J. \& Milgrom, J. Assessing sleep during pregnancy: a study across two time points examining the Pittsburgh Sleep Quality Index and associations with depressive symptoms. Women's health issues: official publication of the Jacobs Institute of Women's Health 19, 45-51, https://doi.org/10.1016/j.whi.2008.10.004 (2009).

16. Buysse, D. J., Reynolds, C. F. 3rd, Monk, T. H., Berman, S. R. \& Kupfer, D. J. The Pittsburgh Sleep Quality Index: a new instrument for psychiatric practice and research. Psychiatry research 28, 193-213 (1989).

17. Johns, M. W. Reliability and factor analysis of the Epworth Sleepiness Scale. Sleep 15, 376-381 (1992).

18. Baumgartel, K. L., Terhorst, L., Conley, Y. P. \& Roberts, J. M. Psychometric evaluation of the Epworth sleepiness scale in an obstetric population. Sleep medicine 14, 116-121, https://doi.org/10.1016/j.sleep.2012.10.007 (2013).

19. Netzer, N. C., Stoohs, R. A., Netzer, C. M., Clark, K. \& Strohl, K. P. Using the Berlin Questionnaire to identify patients at risk for the sleep apnea syndrome. Annals of internal medicine 131, 485-491 (1999).

20. Tantrakul, V. et al. Screening of obstructive sleep apnea during pregnancy: differences in predictive values of questionnaires across trimesters. Journal of clinical sleep medicine: JCSM: official publication of the American Academy of Sleep Medicine 11, 157-163, https://doi.org/10.5664/jcsm.4464 (2015).

21. Walters, A. S. et al. Validation of the International Restless Legs Syndrome Study Group rating scale for restless legs syndrome. Sleep medicine 4, 121-132 (2003).

22. Okun, M. L., Buysse, D. J. \& Hall, M. H. Identifying Insomnia in Early Pregnancy: Validation of the Insomnia Symptoms Questionnaire (ISQ) in Pregnant Women. Journal of clinical sleep medicine: JCSM: official publication of the American Academy of Sleep Medicine 11, 645-654, https://doi.org/10.5664/jcsm.4776 (2015).

23. Zafarghandi, N. et al. The effects of sleep quality and duration in late pregnancy on labor and fetal outcome. The journal of maternalfetal \& neonatal medicine: the official journal of the European Association of Perinatal Medicine, the Federation of Asia and Oceania Perinatal Societies, the International Society of Perinatal Obstet 25, 535-537, https://doi.org/10.3109/14767058.2011.600370 (2012).

24. Li, R. et al. Sleep disturbances during pregnancy are associated with cesarean delivery and preterm birth. The journal of maternal-fetal \& neonatal medicine: the official journal of the European Association of Perinatal Medicine, the Federation of Asia and Oceania Perinatal Societies, the International Society of Perinatal Obstet 1-6, https://doi.org/10.1080/14767058.2016.1183637 (2016).

25. Hung, H. M., Ko, S. H. \& Chen, C. H. The association between prenatal sleep quality and obstetric outcome. The journal of nursing research: JNR 22, 147-154, https://doi.org/10.1097/jnr.0000000000000039 (2014).

26. Hall, W. A., Stoll, K., Hutton, E. K. \& Brown, H. A prospective study of effects of psychological factors and sleep on obstetric interventions, mode of birth, and neonatal outcomes among low-risk British Columbian women. BMC pregnancy and childbirth 12, 78, https://doi.org/10.1186/1471-2393-12-78 (2012).

27. Tsai, S. Y., Lin, J. W., Kuo, L. T., Lee, C. N. \& Landis, C. A. Nighttime sleep, daytime napping, and labor outcomes in healthy pregnant women in Taiwan. Research in nursing \& health 36, 612-622, https://doi.org/10.1002/nur.21568 (2013).

28. Herring, S. J. et al. Do pregnant women accurately report sleep time? A comparison between self-reported and objective measures of sleep duration in pregnancy among a sample of urban mothers. Sleep \& breathing =Schlaf \& Atmung 17, 1323-1327, https://doi. org/10.1007/s11325-013-0835-2 (2013).

29. Bin, Y. S., Cistulli, P. A. \& Ford, J. B. Population-Based Study of Sleep Apnea in Pregnancy and Maternal and Infant Outcomes. Journal of clinical sleep medicine: JCSM: official publication of the American Academy of Sleep Medicine 12, 871-877, https://doi. org/10.5664/jcsm.5890 (2016).

30. Wangel, A. M., Molin, J., Ostman, M. \& Jernstrom, H. Emergency cesarean sections can be predicted by markers for stress, worry and sleep disturbances in first-time mothers. Acta obstetricia et gynecologica Scandinavica 90, 238-244, https://doi. org/10.1111/j.1600-0412.2010.01056.x (2011).

\section{Acknowledgements}

We acknowledge the assistance of Assistant Professor Swee May Cripe of Perdana University, Malaysia in the design of the study and allowing investigators ACAT and AXD to observe and learn from her established field team conducting interviews using the same questionnaires. We also acknowledge the cooperation of care providers of the participants working in the obstetric unit of the University Malaya Medical Centre. University of Malaya funded the study through a block grant (grant identifier UM.C/625/1/HIR/MOHE/MED/28). The funder plays no role in study design, implementation, data analysis or preparation of the manuscript.

\section{Author Contributions}

All authors (A.C.A.T., A.X.D., S.Z.O. and P.C.T.) contributed to the design of the study. P.C.T. conceptualized the study, A.C.A.T. and A.X.D. ran the study and collected the data. A.C.A.T., A.X.D. and P.C.T. did the primary data analysis. A.C.A.T., A.X.D. and P.C.T. co-drafted and S.Z.O. refined the manuscript. All authors approve and claim ownership of the manuscript. P.C.T. is the guarantor for the manuscript.

\section{Additional Information}

Supplementary information accompanies this paper at https://doi.org/10.1038/s41598-017-12410-7.

Competing Interests: The authors declare that they have no competing interests.

Publisher's note: Springer Nature remains neutral with regard to jurisdictional claims in published maps and institutional affiliations.

Open Access This article is licensed under a Creative Commons Attribution 4.0 International

License, which permits use, sharing, adaptation, distribution and reproduction in any medium or format, as long as you give appropriate credit to the original author(s) and the source, provide a link to the Creative Commons license, and indicate if changes were made. The images or other third party material in this article are included in the article's Creative Commons license, unless indicated otherwise in a credit line to the material. If material is not included in the article's Creative Commons license and your intended use is not permitted by statutory regulation or exceeds the permitted use, you will need to obtain permission directly from the copyright holder. To view a copy of this license, visit http://creativecommons.org/licenses/by/4.0/.

(C) The Author(s) 2017 